\title{
The Effect of Wealth Increase on Education and Entertainment Consumption in China
}

\begin{abstract}
Rui Liu ${ }^{1, *}$
${ }^{1}$ University of Bristol

*Email: ruiliu7650@gmail.com

ABSTRACT

Entertainment and education consumption partly reflects people's living standards. In order to study the influencing factors of entertainment and education consumption of Chinese people in the second decade of the 21st century, this paper uses the data from 2010 to 2018 in CFPS and the multiple linear regression method in econometrics to evaluate the impact of the increase of total household assets on the consumption of entertainment and education through Stata software. The results show that the increase in household assets promotes entertainment and education consumption. However, the stimulation effect gradually decreased from 2010 to 2018. In addition, high housing price took in a large amount of family income and impeded the consumption of entertainment and education.
\end{abstract}

Keywords: entertainment and education consumption, wealth, household assets, living condition

\section{INTRODUCTION AND BACKGROUND}

During the industrial Revolution, productivity improved exponentially and human society began to accumulate wealth. However, in China, there was a different story.[1] From the founding of the People's Republic of China in 1949 to the 1980s, China adopted command economic system, and private property was totally illegal. As a result, it was almost impossible for Chinese people to accumulate wealth before 1980s. [1] Since 1980s, China's economic system changed to market economy, allowing individuals to have access to their own private property.[2]

Meanwhile, great changes have taken place in China's consumption structure. Before the 1980s, basic consumption, such as food consumption and clothing, accounted for the vast majority of people's consumption. Now the consumption structure of Chinese people has changed a lot. The food expenditure only accounts for a small part of the total consumption,[3] and people focus on improving the quality of life, instead of striving for survival. Therefore, entertainment and education consumption has also become one of the choices of Chinese people's consumption.

\section{LITERATURE REVIEW}

With the annual data from 1978 to 2004, Hu Ridong analyzed the dynamic influence of urbanization development on urban residents' consumption and rural residents' consumption respectively by using impulse response function and variance decomposition on the basis of establishing vector autoregressive model. The analysis shows that since 1978, China's urbanization development has played a significant role in promoting consumption growth.[4]

Xu Kaige (2021) used the consumption function to build a regression equation, and the results show that there is a negative correlation between the housing price and consumption. But he also points out that the real relationship between real estate investment and consumption is more complex.[5] In addition, Shen Bo and Jiao Hongbing (2021) believe that real estate prices rise on consumption wealth effect or crowding out effect, in foreign countries, the wealth effect is more obvious, but in China, the crowding out effect dominates.[6]

Through a review of the past literature, I found that most of the literature focused on the changes of the structure of Chinese residents' consumption and the impact of urbanization or real estate on consumption, while little research is about education and entertainment consumption. This paper uses multiple linear regression to analyze the impact of the growth of Chinese household wealth on entertainment and education consumption. As the consumption of entertainment and education can reflect people's living standard, it provides a new perspective for studying the changes of Chinese people's living conditions. 


\section{METHODOLOGY}

\subsection{Data and variables}

The data model of this thesis is panel data, which adopts household data in CFPS (China Family Panel Studies). The China Family Panel Studies (CFPS) aims to reflect the social, economic, demographic, educational and health changes in China by tracking and collecting data at the three levels of individuals, families and communities, and provide a data basis for academic research and public policy analysis.

The predicted variable is entertainment and education consumption, and the explanatory variable is total household assets. In addition, some other factors affecting entertainment and education consumption are chosen as control variables, which are savings, family income, family wage, operate income, property income, transfer income, house debts, nonhousing debts, familysize, urban or countryside, health condition and intelligence level respectively.

\subsection{Model setting}

This paper selects the data of 2010, 2012, 2014, 2016 and 2018 in CFPS to construct panel data

To study this topic, firstly, entertainment and education consumption is taken as the predicted variable, total family assets as the explanatory variable, and the remaining variables are controlled variables. Since multiple linear regression is used in this paper, the model is as follows

$$
\mathrm{Y}=\beta_{0}+\beta_{1} \mathrm{x}_{1}+\beta_{2} \mathrm{X}_{2}+\ldots+\beta_{\mathrm{k}} \mathrm{x}_{\mathrm{k}}+\mathrm{u}
$$

\subsection{Empirical analysis}

First of all, with the data mentioned above, the multiple linear regression model is adopted for regression.

Table 1. Multiple linear regression data processing results

\begin{tabular}{|c|c|c|c|c|c|}
\hline & 2010 & 2012 & 2014 & 2016 & 2018 \\
\hline VARIABLES & eec & eec & eec & eec & eec \\
\hline \multirow[t]{2}{*}{ total_asset } & $0.002 * * *$ & $0.002 * * *$ & $0.002 * * *$ & $0.001 * * *$ & $0.001 * * *$ \\
\hline & $(0.000)$ & $(0.000)$ & $(0.000)$ & $(0.000)$ & $(0.000)$ \\
\hline \multirow[t]{2}{*}{ savings } & $0.021 * * *$ & $0.009 * * *$ & $0.006^{* * *}$ & $0.012 * * *$ & $0.007 * * *$ \\
\hline & $(0.002)$ & $(0.001)$ & $(0.001)$ & $(0.001)$ & $(0.001)$ \\
\hline \multirow[t]{2}{*}{ fincome } & $0.039 * * *$ & $0.007 * * *$ & $0.018 * * *$ & $0.009 * * *$ & $0.036^{* * *}$ \\
\hline & $(0.002)$ & $(0.002)$ & $(0.002)$ & $(0.001)$ & $(0.002)$ \\
\hline \multirow[t]{2}{*}{ house_debts } & -0.000 & $0.003 *$ & $0.008 * * *$ & $0.002 * * *$ & $0.007 * * *$ \\
\hline & $(0.003)$ & $(0.002)$ & $(0.001)$ & $(0.000)$ & $(0.001)$ \\
\hline \multirow[t]{2}{*}{ nonhousing_debts } & $0.015 * * *$ & $0.004 * * *$ & $0.008 * * *$ & $0.004 * * *$ & $0.006^{* * *}$ \\
\hline & $(0.002)$ & $(0.001)$ & $(0.001)$ & $(0.001)$ & $(0.001)$ \\
\hline \multirow[t]{2}{*}{ familysize } & $174.650 * * *$ & $298.044 * * *$ & $428.243^{* * *}$ & $616.769^{* * *}$ & $702.006^{* * *}$ \\
\hline & $(48.553)$ & $(47.352)$ & (42.209) & $(51.879)$ & $(53.778)$ \\
\hline \multirow[t]{2}{*}{ Constant } & $426.652 * *$ & $1,139.588 * * *$ & $779.142 * * *$ & $\begin{array}{l}1,135.625^{* *} \\
*\end{array}$ & -44.085 \\
\hline & $(206.880)$ & $(203.461)$ & (177.079) & $(216.654)$ & (223.158) \\
\hline Observations & 13,491 & 11,340 & 12,355 & 13,182 & 13,294 \\
\hline R-squared & 0.123 & 0.085 & 0.109 & 0.123 & 0.186 \\
\hline
\end{tabular}

Standard errors in parentheses

$* * * \mathrm{p}<0.01, * * \mathrm{p}<0.05, * \mathrm{p}<0.1$

The first line is about the impact of family property on entertainment and education consumption. The result shows that family property has a positive correlation with consumption, which means that when the total property increases by one yuan, the consumption for entertainment and education increases by about 0.002 or 0.001 yuan. Therefore, it can be concluded that the increase of family wealth promotes the consumption of entertainment and education. However, the five-year coefficient has changed, which are $0.0020,0.0025$, $0.0017,0.0015$ and 0.0012 respectively. Generally speaking, the coefficient in these five years shows a downward trend, which indicates that with the same increase in wealth of Chinese people, they spend less money on entertainment and education as time went on.
In my opinion, it has something to do with the rapid rise of housing prices in China in recent years. Chinese people spend more money on housing, squeezing the consumption of entertainment and education. [7]

Overall, the impact of total household assets is consistent with Wealth Effect theory. The Wealth Effect theory refers to the influence of the change of residents' net worth on their consumption demand. The more assets people have, the stronger their desire to consume.[8]

Savings are another factor affecting consumption. There is a positive relation between the deposit and the consumption of entertainment and education, namely, the increase of deposit results in the increase of the 
consumption of entertainment and education. As savings increase, anxiety about the risk of losing jobs decreases and people are more willing to consume. As a result, the consumption of entertainment and education will be promoted.

The third row is family income. The result of data processing shows that the coefficient of family income is larger than the coefficient of wealth growth, which means that when family income increases by the same amount as total household assets, the promotion of entertainment and education consumption is greater.

Surprisingly, debt did not act as a brake on consumption. The coefficient of house debt in these five years are either positive or negative, which suggests that in some years debt depressed consumption, and in some years debt and consumption were positively correlated What's more, the coefficients of non-housing debt are all positive in five years, which stimulates the consumption of entertainment and education, perhaps because households use part of non-housing debt for consumption

\section{ROBUSTNESS TEST}

In order to test the reliability of the econometric model, robustness test is also required in this paper. The method of robustness test is as follows. Household net assets, excluding house debts and nonhousing debts, were evaluated as explanatory variable instead of total household assets to test the robustness of the model from the perspective of variables.

Table 2. Robustness test results

\begin{tabular}{|c|c|c|c|c|c|}
\hline VARIABLES & $\begin{array}{l}2010 \\
\text { eec }\end{array}$ & $\begin{array}{l}2012 \\
\text { eec }\end{array}$ & $\begin{array}{l}2014 \\
\text { eec }\end{array}$ & $\begin{array}{l}2016 \\
\text { eec }\end{array}$ & $\begin{array}{l}2018 \\
\text { eec }\end{array}$ \\
\hline \multirow[t]{2}{*}{ net_asset } & $0.002 * * *$ & $0.002 * * *$ & $0.002 * * *$ & $0.001 * * *$ & $0.001 * * *$ \\
\hline & $(0.000)$ & $(0.000)$ & $(0.000)$ & $(0.000)$ & $(0.000)$ \\
\hline \multirow[t]{2}{*}{ savings } & $0.024 * * *$ & $0.009 * * *$ & $0.009 * * *$ & $0.013 * * *$ & $0.009 * * *$ \\
\hline & $(0.002)$ & $(0.001)$ & $(0.001)$ & $(0.001)$ & $(0.001)$ \\
\hline \multirow[t]{2}{*}{ fincome } & $0.042 * * *$ & $0.008 * * *$ & $0.008 * * *$ & $0.010 * * *$ & $0.030 * * *$ \\
\hline & $(0.002)$ & $(0.002)$ & $(0.002)$ & $(0.001)$ & $(0.001)$ \\
\hline \multirow[t]{2}{*}{ house_debts } & 0.001 & $0.006 * * *$ & $0.006 * * *$ & $0.003 * * *$ & $0.009 * * *$ \\
\hline & $(0.003)$ & $(0.002)$ & $(0.002)$ & $(0.000)$ & $(0.001)$ \\
\hline nonhousing_debt & $0.016 * * *$ & $0.007 * * *$ & $0.007 * * *$ & $0.006 * * *$ & $0.008 * * *$ \\
\hline \multicolumn{6}{|l|}{$\mathrm{S}$} \\
\hline & $(0.002)$ & $(0.001)$ & $(0.001)$ & $(0.001)$ & $(0.001)$ \\
\hline \multirow[t]{2}{*}{ familysize } & $193.800 * * *$ & $302.689 * * *$ & $302.689 * * *$ & $623.587 * * *$ & $739.808^{* * *}$ \\
\hline & $(50.273)$ & $(47.058)$ & $(47.058)$ & $(51.473)$ & $(53.873)$ \\
\hline \multirow[t]{2}{*}{ Constant } & 318.306 & $1,113.408 * * *$ & $1,113.408 * * *$ & $1,120.886^{* * *}$ & 175.300 \\
\hline & $(214.486)$ & $(202.101)$ & $(202.101)$ & $(215.170)$ & $(222.723)$ \\
\hline Observations & 13,639 & 11,453 & 11,453 & 13,550 & 13,825 \\
\hline R-squared & 0.122 & 0.085 & 0.085 & 0.122 & 0.179 \\
\hline
\end{tabular}

Standard errors in parentheses

$* * * \mathrm{p}<0.01, * * \mathrm{p}<0.05, * \mathrm{p}<0.1$

The above table examines the impact of household net assets on entertainment and education consumption, excluding the amount of debt in the total assets and also keeping the debts as control variables. The regression results show household net assets have almost the same effect on the entertainment and education consumption as total household assets. In addition, the regression coefficients of control variables are not significantly different from those in the previous table. Overall, the robustness of the data processing can be confirmed.

\section{CONCLUSION}

The increase of household assets has a wealth effect on entertainment and education consumption, that is, the increase of household assets will stimulate entertainment and education consumption. During the nearly ten years from 2010 to 2018, the promotion effect of total household assets on entertainment and education consumption showed a downward trend, which means under the premise of the same increase in household wealth, the increment of entertainment and education consumption declined over the nearly ten years from 2010 to 2018 .

Entertainment and education consumption, to some extent, reflects people's living conditions. The more people spend on entertainment and education, the higher people's living standard will be. From 2010 to 2018, Chinese people's preference for entertainment and education consumption declined, which partly means the increasing pressure of Chinese people to survive and a decline in the quality of life of Chinese people.

\section{REFERENCES}

[1] Yu Xie and Yongai Jin. Household wealth in China. Chinese Sociological Review. 47:3, May 2015 pp. 203-229, 
[2] John Mcmillan and Barry Naughton. How to reform a planned economy: lessons from China. Oxford Review of Economic Policy Vol. 8, No. 1, 1992, pp. 130-143

[3] Xiaohua Yu and David Abler. The demand for food quality in rural China. American Journal of Agricultural Economics Volume91, Issue1 February 2009 Pages 57-69

[4] Hu Ridong and Su Zhifang. Dynamic Analysis of the relationship between urbanization development and consumer consumption growth in China: An empirical study based on VAR Model. CNKI. May 2007

[5] Xu Kaige, Research on the influence of Real estate investment on consumption in China CNKI. February 2020

[6] Shen Bo and Xiao Hongbing, The summary and prospect of the impact of real estate price on the consumption of Chinese residents CNKI. March 2020

[7] Wang Yan, Research on the influence of Chinese household assets on consumption structure CNKI. June 2020

[8] Monica Paiella and Luigi Pistaferri. Decomposing the wealth effect on consumption. The review of economics and statistics. Volume 99, Issue 4, October 2017, pp: 710-721 